\title{
Gaming in Dyscalculia: A Review on disMAT
}

\author{
Filipa Ferraz ${ }^{1}$, António Costa ${ }^{1}$, Victor Alves ${ }^{1}$, Henrique Vicente ${ }^{1,2}$, \\ João Neves ${ }^{3}$, and José Neves ${ }^{1(\varpi)}$ \\ ${ }^{1}$ Centro Algoritmi, Universidade do Minho, Braga, Portugal \\ filipatferraz@gmail.com, \\ \{costa, valves, jneves\}@di.uminho.pt, hvicente@uevora.pt \\ 2 Departamento de Química, Escola de Ciências e Tecnologia, \\ Universidade de Évora, Évora, Portugal \\ ${ }^{3}$ Mediclinic Arabian Ranches, PO Box 282602 Dubai, United Arab Emirates \\ joaocpneves@gmail.com
}

\begin{abstract}
Dyscalculia is a particular learning disability that affects around 6\% of the world population. However, dyscalculics are not brainless; they fight to learn mathematics, notwithstanding nurturing an acceptable education environment at home and school. Indeed, dyscalculic children fall behind early in primary school, and may develop anxiety or a strong dislike of mathematics. When reach adult life are still paid less than ordinary people and have difficulties on handling their ordinary finances. Therefore, this work is about a game; disMAT, which is an app whose purpose entails to appeal children to train their mathematical skills. disMAT involves planning by choosing strategies for change as kids move through the game. Unlike a whole-class mathematics activity, a game may support one's child's individual needs. Undeniably, it must be challenging, have rules and structure, include a clear ending point, and focus on specific abilities.
\end{abstract}

Keywords: Dyscalculia - Gaming therapeutics $\cdot$ Learning disability 